\title{
ANNOTATION
}

\section{The International Congress of Ophthalmology}

In a little over a year's time the Congress of Ophthalmology, which has been arranged under the auspices of various American Ophthalmological Societies, will take place in Washington. We would urge on all British ophthalmic surgeons the desirability of considering ahead, in their arrangements for next year, the possibility of attending this. We fully realize the difficulties that our American confrères will have in securing at the present time anything resembling an International representation at the Congress. The adverse rate of exchange will make it extremely expensive for all European surgeons, and almost prohibitive for some nationalities to go to the United States; but although that will affect British members, it will do so in a much less degree than others. It is only in America that it would be possible to arrange such a Congress at the present time, and we owe it as a duty to our co-workers there to recognize their energy by supporting it by an early subscription, and, wherever possible, by personal attendance. It is not needful to dilate on the hospitality which the inhabitants of the United States show to all their guests. What is of greater importance to us in this country to realize is the vast amount of good work that is being done in ophthalmology in America. We are often accused of insularity in this country, and with some justification. The spirit of provincialism is very rife, and not least so in London itself. It is good for us to get away from it for a time, and in a humble mood of enquiry, wander afield and see what other people are active about in the world. It is in this spirit that we would urge our readers to contemplate seriously the possibility of arranging a visit to Washington in April of next year. The preliminary arrangements for the Congress were published in this journal of February, 1921. The subscription of $\$ 10.00$ should be sent to Dr. Walter R. Parker, 1025 David Whitney Building, Detroit, Michigan, U.S.A. At present rates of exchange, $\$ 10.00$ is equal to $£ 212 \mathrm{~s}$. 6d. (approximately).

\section{ABSTRACTS}

\section{I.-CATARACT}

(I) Darier, A. (Paris).-The surgical treatment. of cataract. (Le traitement chirurgical de la cataracte.) La Clin. Ophtal., August, 1919.

(1) In a space of less than twenty pages, Darier has written a 